\title{
Relationship of Independent Variables with Perception of Farmers' about Impact of Climate Change on Agriculture and Allied Activities
}

\author{
O. P. Parganiha*, V. K. Soni, C. R. Netam and N. K. Toorray \\ IGKV, Raipur (C.G), India \\ *Corresponding author
}

\section{A B S T R A C T}

\section{Keywords}

Climate change, variables, farmers' perception, correlation, multiple regression

\section{Article Info}

Accepted:

22 August 2019

Available Online:

10 September 2019
Climate change is predicted by scientists to have the main impact on agriculture, economy and livelihood of the populations of developing countries. Human expectations regarding weather and climate sometimes lead to perceptions of climate change which are not supported by observational evidences. A better understanding of how farmers' perceive climate change is needed to craft policies and programmes aimed at promoting successful adaptation of the agricultural sector. The present study was carried out in Chhattisgarh state during the years 2016. In this study, the relationship between dependent variables and selected independent variables were ascertained by calculating correlation coefficient (' $r$ ' value) and multiple regression analysis. In case of impact of climate change twenty variables like Age (X1), Educational status (X2), Farming experience (X4), Social participation (X5), Land holding (X7), Irrigation (X8), Annual income (X10), Annual expenditure (X11), Distance to market (X12), Socio-economic status (X13), Crop insurance (X14), Sources of information (X15), Exposure to mass media (X16), Contact with extension personnel (X17), Access to weather forecasts (X18), Cosmopoliteness (X19), Awareness (X20), Innovativeness (X22), Scientific orientation (X23), Risk orientation (X24) were highly and positively significantly correlated with perception of farmers about impact of climate change on agriculture and allied activities (Y2) at 0.05 level of probability. Out of twenty three variables considered in the model, seven variables like age (X1), land holding (X7), irrigation (X8), annual income (X10), exposure to mass media (X16), awareness (X20) and innovativeness (X22) showed significant contribution on predicting perception of farmers' about climate change (Y1) at 0.05 level of probability. It was found that the model developed by considering variables $(\mathrm{X} 1, \mathrm{X} 7, \mathrm{X} 8, \mathrm{X} 10, \mathrm{X} 16, \mathrm{X} 20$ and $\mathrm{X} 22)$ showing significant relationship with dependent variable (Y1) explained highest variation (49.40\%) in predicting perception of farmers' about climate change with significant ' $F$ ' value (32.344) at 5 per cent level of probability. It was found that the model developed by considering variables (X1, $\mathrm{X} 3, \mathrm{X} 8, \mathrm{X} 12, \mathrm{X} 15, \mathrm{X} 20$ and $\mathrm{X} 22$ ) showing significant relationship with dependent variable (Y2) and explained highest variation $(60.80 \%)$ in predicting perception of farmers' about climate change with significant ' $F$ ' value (51.384) at 5 per cent level of probability. 


\section{Introduction}

Like most other developing countries, people in India are dependent to a large extent on its natural resources for livelihood and economy. Any adverse impacts on these natural resources will have repercussion on the nation's livelihood security and economy and widen the gap between the rich and the poor. Climate change is predicted by scientists to have the main impact on agriculture, economy and livelihood of the populations of developing countries and India is one of them, where large parts of the population depend on climate sensitive sectors like agriculture and forestry for livelihood. By adversely affecting freshwater availability and quality, biodiversity and desertification, climate change tends to disproportionately affect the poorest in the society, exacerbating inequities in access to food, water and health.

The capacity to adapt is a function of access to wealth, scientific and technical knowledge, information, skills, infrastructure, institutions and equity and therefore varies among regions and socio-economic groups. Climate change therefore is intrinsically linked to other environmental issues and to the challenge of sustainable development.

In order to understand how human beings would respond to climate change, it is essential to study people's perceptions of climate and the environment in general (Vedwan and Rhoades, 2001). Human expectations regarding weather and climate sometimes lead to perceptions of climate change which are not supported by observational evidences (Rebetcz, 2000). A better understanding of how farmers' perceive climate change, ongoing adaptation measures, and the factors influencing the decision to adapt farming practices is needed to craft policies and programmes aimed at promoting successful adaptation of the agricultural sector
(Bryan et al., 2009). With regards to Chhattisgarh, the state is major producer of rice and is mainly dependent on monsoon rainfall as the irrigation facilities are limited to very small part of the region.

The water supply for domestic purpose, water storage in dams, ground water table, Hydroelectric generation, planning of government policies and schemes etc. are also dependent on monsoon rainfall. Recent studies in climate change in Chhattisgarh indicated that the rainfall pattern has changed during $20^{\text {th }}$ century, fluctuations in the onset and offset of monsoon rainfall, decreasing pattern of rainfall in many districts and also the deficit rainfall years increased during the global worming period.

Climate is getting hotter in the state due to increasing trend for both maximum and minimum temperature, which, has been showed by many of the studies. With this climatic variability, farmers in the state are vulnerable because their livelihood is totally dependent on agriculture.

It is, therefore, an ideal place to study climate change impacts on natural and socio-economic spheres. Such a study would contribute towards a better understanding of the intensity and impacts of global changes. Studies on perceptions, local knowledge, and adaptive strategies at the household and community levels, as well as lessons learned, can provide the basis for concepts and methods of assessing climate change impacts, vulnerability, and adaptation activities of the local farmers.

In this context the present research seeks to ascertain the association between perception of farmers about climate change and impact of climate change with selected independent variables among the farmers of Chhattisgarh Plains. 


\section{Materials and Methods}

The present study was carried out in Chhattisgarh state during the years 2016 in four randomly selected districts out of the total 15 districts of Chhattisgarh Plains namely Raipur, Durg, Balodabazar-Bhatapara and Bemetara. The study was conducted by considering 24 independent variables consisting 5 socio-personal, 9 socioeconomical, 5 communicational and 5 psychological characteristics along with two independent variables $\underline{\text { e.i. }}$ perception of farmers about climate change and impact of climate change on agriculture and allied activities.

The relationship between dependent variable and selected independent variable were ascertained by calculating correlation coefficient (' $r$ ' value) and multiple regression analysis, which was further used to find out the relative importance of different components (independent variables) of dependent variable. Multiple Linear Regression (MLR) analysis is generally considered as an efficient and powerful hypothesis-testing and inference making technique. Since correlation analysis only gives the nature of relationship between dependent and independent variables.

\section{Pearson's Product Moment Correlation Coefficient (r)}

Pearson's correlation coefficient (r) was computed in order to know the nature of relationship between the dependent and selected independent variables. The values of the correlation coefficients were then tested for statistical significance. The coefficient (r) was calculated by using following formulae:

$r_{X Y}=\frac{\sum X Y-\sum X \sum Y / n}{\sqrt{\sum X^{2}-\left(\sum X\right)^{2} / n \sqrt{\sum Y^{2}-\left(\sum Y\right)^{2} / n}}}$
Where,

$\mathrm{r} \quad=$ Co-efficient of correlation between $\mathrm{X}$ and $\mathrm{Y}$

$\sum X \quad=$ Sum of scores of variable $\mathrm{X}$

$\sum Y=$ Sum of scores of variable $\mathrm{Y}$

$\sum X Y=$ Sum of product of $\mathrm{X}$ and $\mathrm{Y}$ variable

$\sum X^{2}=$ Sum of the squares of $X$ variable

$\sum X^{2}=$ Sum of the squares of $Y$ variable

$\mathrm{n} \quad=$ Size of the sample

\section{Multiple regression analysis}

Multiple linear regression analysis was calculated to find out the extent of relationship between dependent and selected independent variables and to know the influence of independent variables on perception of farmers about climate change and its impact on agriculture and allied activities. Further, the computed ' $b$ ' values (regression coefficients) were tested with ' $t$ ' test for its significance.

$\mathrm{Y}=\mathrm{a}+\mathrm{b}_{1} \mathrm{X}_{1}+\mathrm{b}_{2} \mathrm{X}_{2}+\mathrm{B}_{3} \mathrm{X}_{3}+\ldots+\mathrm{B}_{\mathrm{t}} \mathrm{X}_{\mathrm{t}}+\mathrm{e}$

Where,

$\mathrm{Y} \quad=$ the variable that we are trying to predict

$\mathrm{Xi}=$ the variable that we are using to predict $\mathrm{Y}$

a $\quad=$ the intercept

$\mathrm{b}=$ the slope (regression coefficient)

e $\quad=$ the regression residual.

\section{The Coefficient of Determination $\left(\mathrm{R}^{2}\right)$}

This represents the proportion of the total sample variability in $\mathrm{Y}$ that is explained by a linear relationship between $\mathrm{X}$ and $\mathrm{Y} . \mathrm{R}^{2}$ is always less than unit and expressed in percentage. It means the extent of variation in dependent variable (Y) which can be explained by the independent variables (Xi) together. R-Squared measures how well the model fits the data. Values of $\mathrm{R}^{2}$ to 1 fit well. Values of $R^{2}$ close to 0 fit badly. Coefficient of multiple regression $\left(\mathrm{R}^{2}\right)$ was calculated by

$\mathrm{R}^{2}=\frac{S S(Y)-S S E}{S S(Y)}$ 
Where,

$\mathrm{R}^{2} \quad=$ Coefficient of multiple regression

$S S(Y)=$ Sum of squares of dependent variable $(\mathrm{Y})$

SSE $=$ Sum of squires due to deviation from regression

\section{Results and Discussion}

Determination of relationship between dependent and independent variables might help the identification of explanatory variables to describe in better way the farmer's perception about climate change and its impact on agriculture and allied activities. Correlation and linear regression analysis were worked out to find out the nature and extent of relationship between dependent and selected independent variables. Accordingly the results are presented and discussed under following categories.

\section{Correlation analysis among independent and dependent variables}

To determine the degree and nature of relationship and direction of association among independent and dependent variables a correlation analysis were worked out and presented in the form of correlation matrix in Table 1. Out of twenty four independent variables taken in the study, eighteen variables like Age (X1), Educational status (X2), Farming experience (X4), Social participation (X5), Land holding (X7), Irrigation (X8), Annual income (X10), Annual expenditure (X11), Distance to market (X12), Socioeconomic status (X13), Crop insurance (X14), Sources of information (X15), Contact with extension personnel (X17), Cosmopoliteness (X19), Awareness (X20), Innovativeness (X22), Scientific orientation (X23), Risk orientation (X24) were highly and positively significantly correlated with perception of farmers about climate change (Y1) at 0.05 level of probability.

In case of impact of climate change twenty variables like Age (X1), Educational status (X2), Farming experience (X4), Social participation (X5), Land holding (X7), Irrigation (X8), Annual income (X10), Annual expenditure (X11), Distance to market (X12), Socio-economic status (X13), Crop insurance (X14), Sources of information (X15), Exposure to mass media (X16), Contact with extension personnel (X17), Access to weather forecasts (X18), Cosmopoliteness (X19), Awareness (X20), Innovativeness (X22), Scientific orientation (X23), Risk orientation (X24) were highly and positively significantly correlated with perception of farmers about impact of climate change on agriculture and allied activities (Y2) at 0.05 level of probability, while, only one variable i.e. occupation (X6) was highly and negatively significantly correlated with perception of farmers about impact of climate change on agriculture and allied activities (Y2) at 0.05 level of probability.

Independent variables like size of family (X3), access to credit (X9) and decision making pattern (X21) were showing non-significant correlation with both the dependent variables Y1 and Y2.

Most of the independent variables were positively significantly correlated with one another, while some of the variables were showing negative and significant correlation with one another. Only one variable i.e. decision making pattern was significantly correlated with a little number of independent variables.

\section{Multiple regression analysis}

To determine the strength of the relationship between both the dependent variables and independent variables considered under study regression analysis were worked out separately. The analysis consisted of choosing and fitting an appropriate model, done by the method of step down regression analysis, with a view to exploiting the relationship between the variables to help estimate the expected 
response for a given value of the independent variable.

\section{Multiple regression analysis of independent variables with perception of farmers' about climate change}

To find out the best predictor and appropriate fit model for predicting perception of farmers' about climate change a step down multiple regression analysis was worked out. In each step of analysis one variable was dropped that showing more than 10 and maximum value of variable inflation factor (VIF). In this way best fit model was found by dropping the variable i.e., expenditure (X11) and presented in Table 2.
Out of twenty three variables considered in the model, seven variables like age (X1), land holding (X7), irrigation (X8), annual income (X10), exposure to mass media (X16), awareness (X20) and innovativeness (X22) showed significant contribution on predicting perception of farmers' about climate change (Y1) at 0.05 level of probability. The model revealed that 52.50 per cent of the variation in perception of farmers about climate change (Y1) can be explained by considering twenty three independent variables and one dependent variable (Y1). The model is significant in predicting dependent variable (Y1) with 10.391 ' $F$ ' value at 0.05 level of probability.

\section{Conceptual Model of Study}

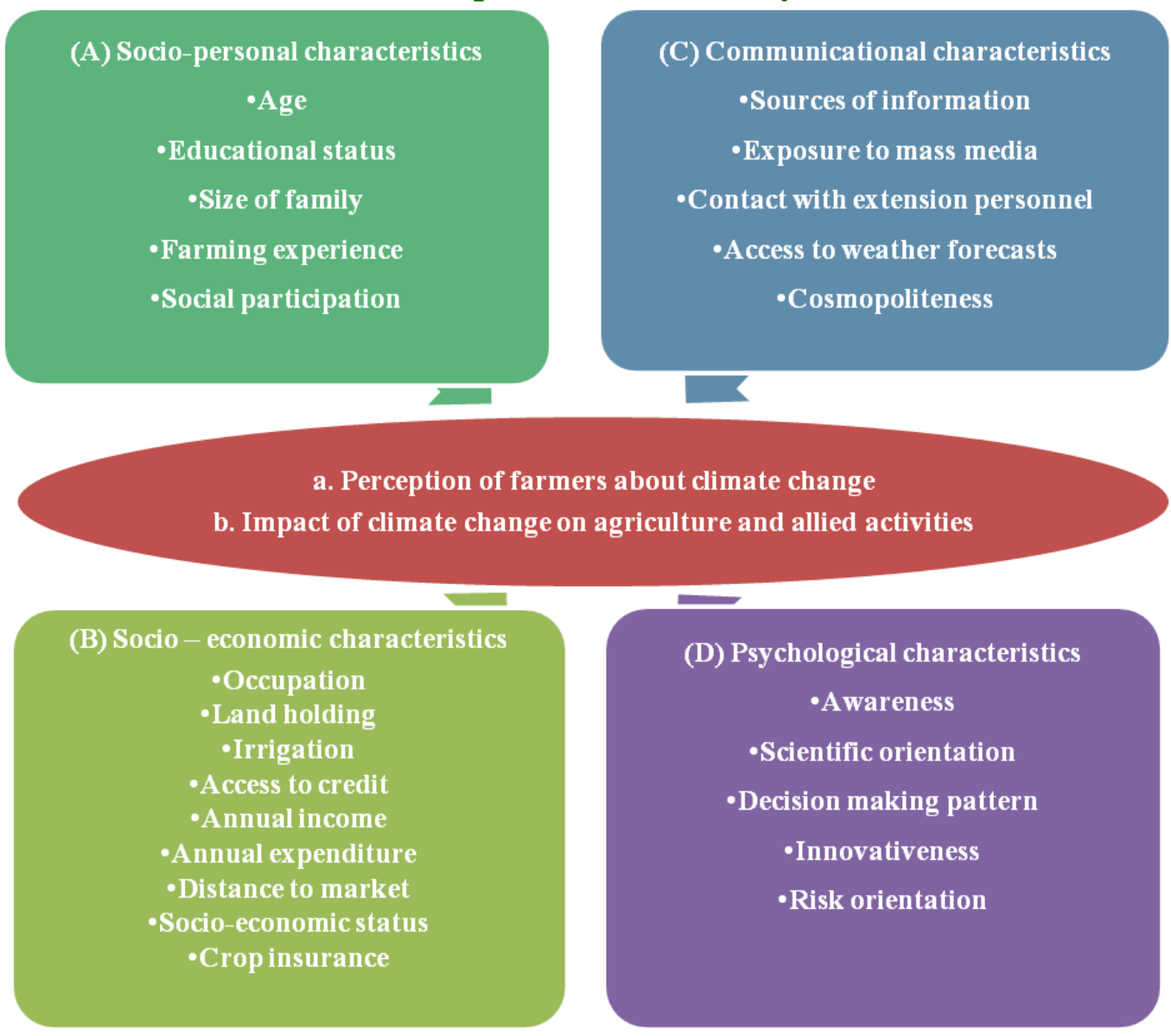


Table.1 Correlation matrix of selected independent and dependent variables

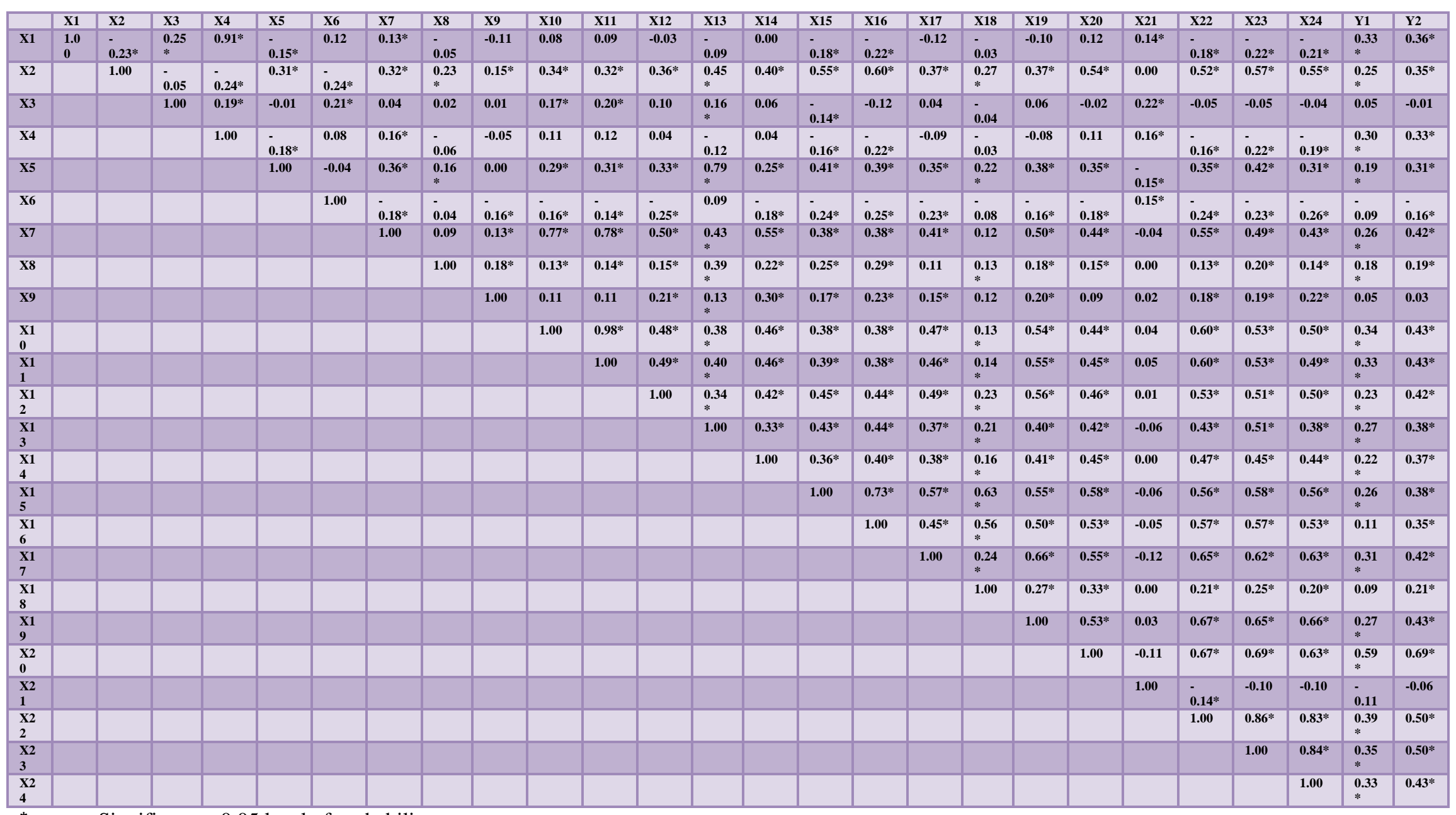

Significant at 0.05 level of probability 
Table.2 Multiple regression analysis of best fit model among selected independent variables with perception of farmers' about climate change

\begin{tabular}{|ll|c|c|}
\hline \multirow{2}{*}{ Variables } & \multicolumn{2}{|c|}{ Regression coefficient } \\
\cline { 2 - 3 } & \multicolumn{1}{|c|}{ 'b' value } & 't' value \\
\hline X1 & Age & $0.146^{*}$ & 2.337 \\
\hline X2 & Educational status & 0.473 & 1.244 \\
\hline X3 & Size of family & -0.380 & -0.817 \\
\hline X4 & Farming experience & -0.002 & -0.030 \\
\hline X5 & Social participation & 0.098 & 0.686 \\
\hline X6 & Occupation & -0.236 & -0.697 \\
\hline X7 & Land holding & $-0.254^{*}$ & -2.011 \\
\hline X8 & Irrigation & $0.800^{*}$ & 2.571 \\
\hline X9 & Access to credit & 1.186 & 1.316 \\
\hline X10 & Annual income & $0.020^{*}$ & 2.578 \\
\hline X12 & Distance to market & -0.178 & -0.381 \\
\hline X13 & Socio-economic status & 0.309 & 0.384 \\
\hline X14 & Crop insurance & -0.634 & -0.946 \\
\hline X15 & Sources of information & 0.324 & 0.916 \\
\hline X16 & Exposure to mass media & $-2.304^{*}$ & -4.626 \\
\hline X17 & Contact with extension personnel & 0.067 & 0.238 \\
\hline X18 & Access to weather forecasts & 0.030 & 0.067 \\
\hline X19 & Cosmopoliteness & -0.305 & -0.548 \\
\hline X20 & Awareness & $0.568^{*}$ & 6.490 \\
\hline X21 & Decision making pattern & -0.033 & -1.314 \\
\hline X22 & Innovativeness & $0.213^{*}$ & 2.266 \\
\hline X23 & Scientific orientation & -0.219 & -1.283 \\
\hline X24 & Risk orientation & 0.012 & 0.105 \\
\hline
\end{tabular}

*Significant at 0.05 level of probability

Multiple $\mathrm{R}^{2}=0.525, \quad$ Intercept $=6.956$,

' $F$ ' Value $=10.391$ at $23,216 \mathrm{df}$

Table.3 Multiple regression analysis of selected model among independent variables with perception of farmers' about climate change

\begin{tabular}{|ll|c|c|}
\hline \multirow{2}{*}{ Variables } & \multicolumn{2}{|c|}{ Regression coefficient } \\
\cline { 3 - 4 } & 'b' value & 't' value \\
\hline X1 & Age & $0.120^{*}$ & 4.386 \\
\hline X7 & Land holding & -0.205 & -1.874 \\
\hline X8 & Irrigation & $0.881^{*}$ & 3.316 \\
\hline X10 & Annual income & $0.015^{*}$ & 2.024 \\
\hline X16 & Exposure to mass media & $-1.785^{*}$ & -4.677 \\
\hline X20 & Awareness & $0.599^{*}$ & 8.028 \\
\hline X22 & Innovativeness & $0.156^{*}$ & 2.326 \\
\hline
\end{tabular}

*Significant at 0.05 level of probability

Multiple $\mathrm{R}^{2}=0.494$, Intercept $=4.719$,

'F' Value $=32.344$ at $07,232 \mathrm{df}$ 
Table.4 Multiple regression analysis of best fit model among selected independent variables with perception of farmers' about impact of climate change on agriculture and allied activities

\begin{tabular}{|ll|c|c|}
\hline \multirow{2}{*}{ Variables } & \multicolumn{2}{|c|}{ Regression coefficient } \\
\cline { 2 - 3 } & & & \multicolumn{2}{|c|}{ 'b' value } \\
\hline X1 & Age & $0.422^{*}$ & 3.522 \\
\hline X2 & Educational status & 0.577 & 0.789 \\
\hline X3 & Size of family & $-2.327^{*}$ & -2.602 \\
\hline X4 & Farming experience & 0.024 & 0.204 \\
\hline X5 & Social participation & 0.182 & 0.662 \\
\hline X6 & Occupation & -0.738 & -1.132 \\
\hline X7 & Land holding & -0.278 & -1.144 \\
\hline X8 & Irrigation & $0.901 *$ & 2.015 \\
\hline X9 & Access to credit & -1.883 & -1.086 \\
\hline X10 & Annual income & 0.017 & 1.133 \\
\hline X12 & Distance to market & $1.518^{*}$ & 2.120 \\
\hline X13 & Socio-economic status & 1.362 & 0.879 \\
\hline X14 & Crop insurance & 0.801 & 0.621 \\
\hline X15 & Sources of information & $-0.844 *$ & -2.142 \\
\hline X16 & Exposure to mass media & -0.131 & -0.136 \\
\hline X17 & Contact with extension personnel & 0.504 & 0.934 \\
\hline X18 & Access to weather forecasts & 0.240 & 0.277 \\
\hline X19 & Cosmopoliteness & 0.664 & 0.621 \\
\hline X20 & Awareness & $0.912^{*}$ & 5.412 \\
\hline X21 & Decision making pattern & -0.009 & -0.187 \\
\hline X22 & Innovativeness & $0.211^{*}$ & 2.106 \\
\hline X23 & Scientific orientation & 0.231 & 0.705 \\
\hline X24 & Risk orientation & -0.125 & -0.564 \\
\hline
\end{tabular}

*Significant at 0.05 level of probability

Multiple $\mathrm{R}^{2}=0.632, \quad$ Intercept $=49.078$,

'F' Value $=16.106$ at $15,216 \mathrm{df}$

Table.5 Multiple regression analysis of selected model among independent variable with perception of farmers' about impact of climate change on agriculture and allied activities

\begin{tabular}{|ll|c|c|}
\hline \multirow{2}{*}{ Model wise Variables } & \multicolumn{2}{|c|}{ Regression coefficient } \\
\cline { 3 - 4 } & 'b' value & 't' value \\
\hline X1 & Age & $0.404^{*}$ & 7.809 \\
\hline X3 & Size of family & $-1.741^{*}$ & -2.255 \\
\hline X8 & Irrigation & $1.302^{*}$ & 2.585 \\
\hline X12 & Distance to market & $1.997^{*}$ & 2.487 \\
\hline X15 & Sources of information & -0.290 & -0.597 \\
\hline X20 & Awareness & $1.069^{*}$ & 7.188 \\
\hline X22 & Innovativeness & $0.365^{*}$ & 3.120 \\
\hline
\end{tabular}

*Significant at 0.05 level of probability

Multiple $\mathrm{R}^{2}=0.608$, Intercept $=48.318$,

' $\mathrm{F}$ ' Value $=51.384$ at $06,232 \mathrm{df}$ 
Among above discussed twenty three independent variables various models were developed and tested for finding their predicting ability for variation in the perception of farmers' about climate change (Y1). The best model was picked out and presented in Table 3. It was found that the model developed by considering variables (X1, X7, X8, X10, X16, X20 and X22) showing significant relationship with dependent variable (Y1) explained highest variation $(49.40 \%)$ in predicting perception of farmers' about climate change with significant ' $F$ ' value (32.344) at 5 per cent level of probability.

These findings are in partial accordance with those reported by Shiferaw and Holden (1998) that age of the head of household can be used to capture farming experience, Nhemachena and Hassan (2007) argued that higher age with highly experienced farmers are likely to have more information and knowledge on changes in climatic conditions and crop and livestock management practices. They also discovered that higher income farmers might however be less risk-averse and have enough access to information and access to extension services with mass media exposure was one of the important determinants of farmers perception on climate change and farm-level adaptation. Total size of farm area also had positive effect on climate change perceptions but the likelihood of farmers' adaptation to climate change varied.

\section{Multiple regression analysis of independent variables with perception of farmers' about impact of climate change on agriculture and allied activities}

To find out the best predictor and appropriate fit model for predicting perception of farmers' about impact of climate change on agriculture and allied activities a step down multiple regression analysis was worked out. In each step of analysis one variable was dropped that showing more than 10 and maximum value of variable inflation factor (VIF). In this way best fit model was found by dropping the variable i.e., expenditure (X11) and presented in Table 4.

Out of twenty three variables considered in the model, seven variables like age (X1), size of family (X3), irrigation (X8), distance to market (X12), sources of information (X15), awareness (X20) and innovativeness (X22) showed significant contribution on predicting perception of farmers' about impact of climate change on agriculture and allied activities (Y2) at 0.05 level of probability. The model revealed that 63.20 per cent of the variation in perception of farmers about impact of climate change on agriculture and allied activities (Y2) can be explained by considering twenty three independent variables and one dependent variable (Y2). The model is significant in predicting dependent variable (Y2) with 16.106 ' $\mathrm{F}$ ' value at 0.05 level of probability.

Among above discussed twenty three independent variables, various models were developed and tested for finding their predicting ability for variation in the perception of farmers' about impact of climate change on agriculture and allied activities (Y2). The best model was picked out and presented in Table 5. It was found that the model developed by considering variables (X1，X3，X8，X12，X15, X20 and X22) showing significant relationship with dependent variable (Y2) explained highest variation $(60.80 \%)$ in predicting perception of farmers' about climate change with significant ' $F$ ' value (51.384) at 5 per cent level of probability.

These findings are supported by the results reported by Mandleni (2011) that access to extension services was positively related to climate change impacts. Among the exogenous variables, it was the only variable that had the highest weighting coefficient. 
Nhemachena and Hassan (2007) stated that raising awareness of changes in climatic conditions among farmers would have greater impact in increasing adaptation to changes in climatic conditions. Households that had large sizes were therefore expected to have enough labour to take up adaptation measures in response to climate change impacts (Hassan and Nhemachena, 2008). Zhang and Flick (2001) however, found that long distances to input markets decreased the likelihood of adaptation against climate change impacts. Innovative farmers perceive more about climate change impacts.

As the understanding on global climate and its change is pre requisite to take appropriate initiatives to combat climate change. Hence, it is essential to study farmers' perceptions to understand how farmers would respond to climate change and its impact on agriculture. The study was carried out to measure perception of farmers about climate change and impact of climate change on agriculture and allied activities considering as dependent variables. These tactical observations were influenced by a number of socio-personal, socio-economic, communicational and sociopsychological factors as independent variables. As per the findings many characteristics of the farmers like age, availability of irrigation facilities, awareness are innovativeness were the most important determinants to measure farmers perception on climate change.

\section{References}

Bryan, E., Deressa, T. T., Gbetibouo, G. A. and Ringler, C. 2009. Adaptation to climate change in Ethiopia and South Africa: options and constraints. Environmental Science and Policy 12 (4): 413-426.

Hassan, R. and Nhemachena, C. 2008. Determinants of African farmers' strategies for adaptation to climate change: Multinomial choice analysis. African Journal of Agricultural and Resource Economics 2 (1): 83-104.

Mandleni, B. 2011. Impact of climate change and adaptation on cattle. Ph.D. Thesis, Environmental Management, University of South Africa.

Nhemachena, C. and Hassan, R. 2007. Microlevel analysis of farmers' adaptation to climate change in Southern Africa, IFPRI Discussion Paper No. 00714, International Food Policy Research Institute, Washington DC, USA.

Rebetcz, M. 2000. Public expectations as an element of human perceptions of climate change. Climatic change, Springer, Netherlands 32:.495- 509.

Shiferaw, B. and Holden, S. 1998. Resource degradation and adoption of land conservation technologies in the Ethiopian highlands: case study in Andit Tid, North Shewa. Agricultural Economics 27 (4) (1998): 739-752.

Vedwan, N. and Rhoades, R. E. 2001. Climate change in the western Himalayas of India : A study of local perceptions and response. Climate Research 19: 109- 117.

Zhang, D. and Flick, W. 2001. Sticks, carrots, and reforestation investment. Land Economics 77 (3): 443-56.

\section{How to cite this article:}

Parganiha, O. P., V. K. Soni, C. R. Netam and Toorray, N. K. 2019. Relationship of Independent Variables with Perception of Farmers' about Impact of Climate Change on Agriculture and Allied Activities. Int.J.Curr.Microbiol.App.Sci. 8(09): 2178-2187.

doi: https://doi.org/10.20546/ijcmas.2019.809.251 